\title{
A Systematic Overview of Learning Analytics in Higher Education
}

\author{
Lin Zhong \\ The University of Southern Mississippi
}

\begin{abstract}
Learning analytics has been an emerging trend in education especially in higher education. This study aims to provide a comprehensive understanding of learning analytics in higher education through an overview of current research topics of learning analytics in higher education, significant results of previous studies, and implications in future research. Results show that research topics of learning analytics in higher education fall into five categories: learning, teaching, administration, technology development, and digital citizenship. More studies are required in learning prediction and data variety.
\end{abstract}

Keywords: Learning Analytics, Higher Education, Research Trend

\section{Introduction}

Along with a greater influence of technology in education, nowadays almost everything in schools, especially higher education, is running digitally. Many universities have information management system where students can register classes, pay tuition, and evaluate classes. Many universities are using Learning Management Systems (LMSs), which enable the management and online class delivery of courses through the university, while allowing students to interact with instructors and peers through their course experiences. During the interaction process, large amounts of data are generated, such as questions numbers, email numbers, assignment grades, LMS logs, and navigation paths. These automatically generated data contains a lot of useful information from which some researchers utilize analytics techniques to explore learning performance patterns and try to predict future learning behaviors (Mattingly, Rice, \& Berge, 2012).

In fact, using such analytics techniques are not a new concept. Analytics techniques have been widely used in business and medical areas. Amazon's recommendation email is a good example of applying analytics techniques in business. Analytics techniques are also used to support business data-drive decisions, such as customer service improvement and response development to potential issues (Calof, Richards, \& Smith, 2015). Medical organizations use analytics techniques to study patients' data so that patients can get personalized treatments (Wills, 2014). 
Recently, universities are facing significant issues, such as student retention, financial crisis, and globalization. After witnessing the benefits of analytics techniques in other fields, universities began to seek solutions through analytics technique. Therefore, analytics techniques are introduced into the educational field, which is referred as academic analytics (Campell, DeBlois, \& Oblinger, 2007). Academic analytics is defined as "a process of providing higher education institutions with the data necessary to support operational and financial decision making" (van Barneveld, Arnold, \& Campbell, 2012, p. 8). Academic analytics, along with data mining and Course Management Systems (CMSs), has the potential to support institutional decisions (Baepler \& Murdoch, 2010). For instance, the University of Central Florida utilized academic analytics to predict students' withdrawal and success based on the course modality (Dziuban, Moskal, Cavanagh, \& Watts, 2012).

Different from academic analytics, learning analytics focuses on the learning process (Long \& Siemens, 2011). At 1st International Conference on Learning Analytics (Ferguson \& Buckingham Shum, 2011), learning analytics was defined as "the measurement, collection, analysis, and reporting of data about learners and their contexts, for the purposes of understanding and optimizing learning and the environments in which it occurs." (Siemens, 2013, p 253).

Currently, higher education has made great improvements in learning analytics. However, most practices of learning analytics in higher education are limited to learning analytics system and platform development. Learning analytics in higher education should not be restricted to technology development. Educators, especially higher education educators, need to go beyond the learning analytics system development and consider how learning analytics can be integrated into higher education to improve learning, teaching, and administration. This study aims to investigate the current research topics of learning analytics in higher education and where learning analytics should go beyond the learning analytics system development in higher education.

\section{Purpose of the Study}

The purpose of this study is to provide an overview of how learning analytics has been studied in higher education. Research objectives of the study include (a) current research topics of learning analytics in higher education, (b) significant research results, and (c) future research directions. Researching current research on learning analytics in higher education can help educators get deeper understanding of applying learning analytics in higher education.

Another goal of this study is to direct future research efforts of learning analytics in higher education. Learning analytics is still in its infancy stage. Educators have a lot of concerns about the application of learning analytics in higher education. This study contributes to the research community by providing a clear picture of learning analytics in higher education and exploring the future research directions of learning analytics in higher education from an instructional designer's perspective.

\section{Research Questions}

This study aims to investigate how learning analytics has been applied in higher education. The following research questions are proposed:

1) What are the research topics of learning analytics in the context of higher 
education?

2) What are significant results of the learning analytics research in higher education?

3) What do these results indicate for the future learning analytics research in higher education?

\section{Methodology}

This study uses systematic review methodology to explore the literature related to learning analytics in the context of higher education. According to Khan, Kunz, Kleijnen, and Antes (2003), systematic review constitutes five steps: (a) compose research questions, (b) search relevant articles, (c) assess the quality of articles, (d) summarize the results, and (e) interpret the findings. As research questions were proposed in the above section, this section focuses on searching and assessing the relevant literature. Results are summarized and interpreted in the next section.

In order to identify all relevant articles, multiple databases were examined: Educational Source, ERIC, IEEE Computer Society Digital Library, Science Direct, Inspec, SpringLink, and Google Scholar. Multiple key words were used during the searching process, including learning analytics, higher education learning analytics, university learning analytics, and academic analytics. The article selection criteria is:

(a) Academic publications, including academic journals, conference proceedings, and workshop proceedings;

(b) Articles have full text access;

(c) Articles' research context is higher education;

(d) Articles' research topic is learning analytics.

There were 265 articles that met the inclusion criteria after duplicated articles were excluded. To assess the quality of the search results, the following rubrics were used during the assessment process:

(a) Methodology design is rigorous;

(b) Results are clearly presented;

(c) Sampling method is representative of the population;

After selection and assessment of literature, 60 articles were identified for this study. Then the 60 articles were classified and interpreted based on the research purposes, research design, research setting, data analysis methods, and research results.

\section{Results}

In this section, search results are presented according to the publication year and type, data sources, and research topics.

Based on the publication year and type, publications of learning analytics in higher education have increased since 2010 and achieved to the highest number in 2013, as illustrated in Figure 1. Publications began to decrease in 2014 and followed by 2015 . Conference publications are more stable compared to journal publications.

According to Figure 1, publications of learning analytics began to increase in 2010 and decrease after 2013. Conference publications have increased dramatically since 2011. The 1st International Conference on Learning Analytics, which was held 
in 2011 in Canada, may be the reason for increased conference publications. The decreasing number of both conference and journal publications after 2013 maybe cause by inadequate technological support and ethical issues as shown in Table 3. Although many researchers tried to develop appropriate platforms or tools to improve learning analytics application in higher education, significant results from Table 3 show that few platforms and tools can be generalized and utilized in different situations. In addition, ethical issues still need more research even though some principles and framework have been proposed.
Data sources of learning analytics include Learning Management Systems (LMSs), Course Management Systems (CMSs), Student Information Systems (SISs), hard copy documentations, and data generated by external platforms. LMS and external platforms are the primary data sources for learning analytics as illustrated in Table 1. Some researchers combined various data sources to generate a complete picture of the targeted research questions (Dziuban et al., 2012; Fidalgo-Blanco, Sein-Echaluce, GarcíaPeñalvo, \& Conde, 2015).

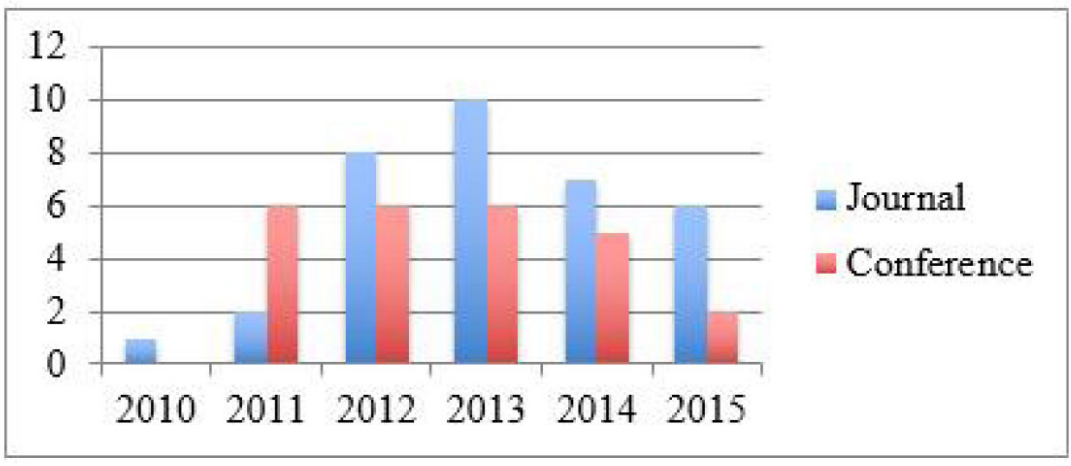

Figure 1. Tweet Frequency Histogram.

Table 1. Articles categories based on learning analytics data sources

Arnold \& Pistilli, (2012); Barber \& Sharkey (2012); Dimopoulos, Petropoulou, \& Retalis (2013); Dyckhoff, Zielke, Bültmann, Chatti, \& Schroeder (2012); Dziuban et al., (2012); Fidalgo-Blanco et al., (2015); Grant (2012); Hernández-García,

LMS González-González, Jiménez-Zarco, \& Chaparro-Peláez (2015); Ifenthaler \& Widanapathirana (2014); Jo, Kim, \& Yoon (2014); Ma, Han, Yang, \& Cheng (2015); Olmos \& Corrin (2012); Phillips et al., (2011); Ruipérez-Valiente, Muñoz-Merino, Leony, \& Kloos (2015); Yu \& Jo (2014);

CMS Baepler \& Murdoch (2010); Dziuban et al., (2012); Sharkey (2011);

SIS Barber \& Sharkey (2012); Dziuban et al., (2012); Sharkey (2011); Yasmin (2013); Agudo-Peregrina, Iglesias-Pradas, Conde-González, \& Hernández-García (2014); Blikstein (2011); Dziuban et al., (2012); Ferguson \& Buckingham Shum (2011);

External Fernandez-Medina, Pérez-Pérez, Álvarez-García, \& del Puerto Paule-Ruiz (2013);

Platform Fidalgo-Blanco et al., (2015); Koulocheri \& Xenos (2013); Olmos \& Corrin (2012); Pardo \& Kloos (2011); Serrano-Laguna, Torrente, Moreno-Ger, \& FernándezManjón (2014); Tabaa \& Medouri (2013);

Hard copy Gibson, Kitto, \& Willis (2014); Grant (2012); Olmos \& Corrin (2012); 
The articles are also categorized by research topics. Research topics of learning analytics in higher education fall into five categories based on the research purposes: learning, teaching, administration, technology development, and digital citizenship. Articles focused on technology development have the largest number of publications, which account for $38 \%$ of the total publications. Articles focused on learning account for $25 \%$ of the entire publications. Publications related to teaching accounted for $17 \%$, which is a little bit higher than the $10 \%$ of administration and digital citizenship publications.

\section{Discussion}

\section{- RQ1: What are the research topics of learning analytics in higher education?}

After the assessment process, qualitative research methods were used to analyze and interpret the search results. Based on the results, learning analytics research in higher education falls into five categories, including learning, teaching, administration, technology development, and digital citizenship.

Table 2. Research topics of learning analytics in higher education

\begin{tabular}{|c|c|c|}
\hline \multirow[t]{2}{*}{ Learning } & $\begin{array}{l}\text { Learning } \\
\text { Behavior Monitor } \\
\text { \& Evaluation }\end{array}$ & $\begin{array}{l}\text { de Laat \& Prinsen (2014); Ferguson \& Buckingham Shum (2011); } \\
\text { Fidalgo-Blanco et al., (2015); Hernández-García et al., (2015); } \\
\text { Kruse \& Pongsajapan (2012); Lonn, Aguilar, \& Teasley (2015); } \\
\text { Olmos \& Corrin (2012); Phillips et al., (2011); Serrano-Laguna, } \\
\text { Torrente, Moreno-Ger \& Fernández-Manjón (2014); Serrano- } \\
\text { Laguna, Torrente, Moreno-Ger, \& Fernández-Manjón (2012); Yu \& } \\
\text { Jo (2014); }\end{array}$ \\
\hline & $\begin{array}{l}\text { Learning } \\
\text { Performance } \\
\text { Prediction }\end{array}$ & Agudo-Peregrina et al., (2014); Mattingly et al., (2012); \\
\hline \multirow[t]{2}{*}{ Teaching } & $\begin{array}{l}\text { Instructional } \\
\text { Reflection \& } \\
\text { Intervention }\end{array}$ & $\begin{array}{l}\text { Baepler \& Murdoch (2010); Clow (2013); Dietz-Uhler \& Hurn } \\
\text { (2013); Dyckhoff, Lukarov, Muslim, Chatti \& Schroeder (2013); } \\
\text { Dyckhoff (2011); Dyckhoff et al., (2012); Wise (2014); }\end{array}$ \\
\hline & $\begin{array}{l}\text { Instructional } \\
\text { Design }\end{array}$ & $\begin{array}{l}\text { Grant (2012); Lockyer, Heathcote, \& Dawson (2013); Lockyer \& } \\
\text { Dawson (2011); }\end{array}$ \\
\hline Administration & $\begin{array}{l}\text { Data-Driven } \\
\text { Decision Making }\end{array}$ & $\begin{array}{l}\text { Dziuban at al., (2012); Friesen (2013); Picciano (2012); Yasmin } \\
\text { (2013); Sharkey (2011); }\end{array}$ \\
\hline \multirow{2}{*}{$\begin{array}{l}\text { Technology } \\
\text { Development }\end{array}$} & $\begin{array}{l}\text { Platforms } \\
\text { Development }\end{array}$ & $\begin{array}{l}\text { Arnold \& Pistilli (2012); Dimopoulos et al., (2013); Ferguson } \\
\text { \& Buckingham Shum (2011); Fortenbacher et al., (2013); Jo et } \\
\text { al., (2014); Koulocheri \& Xenos (2013); Pardo \& Kloos (2011); } \\
\text { Rayón, Guenaga, \& Núñez (2014); Ruipérez-Valiente et al., (2015); } \\
\text { Tabaa \& Medouri (2013); Verbert et al., (2014); Blikstein (2011); }\end{array}$ \\
\hline & $\begin{array}{l}\text { Framework/ } \\
\text { Model } \\
\text { Development }\end{array}$ & $\begin{array}{l}\text { Ali, Asadi, Gašević, Jovanović, \& Hatala (2013); Clow (2012); } \\
\text { Dyckhoff et al., (2013); Gibson et al., (2014); Ifenthaler \& } \\
\text { Widanapathirana (2014); van Barneveld et al. (2012); Wise, Zhao, } \\
\text { \& Hausknecht (2013); Prinsloo, Slade, \& Galpin (2015); }\end{array}$ \\
\hline $\begin{array}{l}\text { Digital } \\
\text { Citizenship }\end{array}$ & $\begin{array}{l}\text { Ethical Issues \& } \\
\text { Privacy }\end{array}$ & $\begin{array}{l}\text { Gašević, Dawson, \& Siemens (2015); Pardo \& Siemens (2014); } \\
\text { Prinsloo \& Slade (2015); Slade \& Galpin (2012); Slade \& Prinsloo } \\
\text { (2013); }\end{array}$ \\
\hline
\end{tabular}




\subsection{Learning}

Learning behavior monitor and evaluation. Most studies of learning analytics in higher education focus on learning participation and performance evaluation (de Laat \& Prinsen, 2014; Hernández-García et al., 2015; Kruse \& Pongsajapan, 2012; Olmos \& Corrin, 2012; Phillipset al,, 2011; Serrano-Laguna et al., 2014; Serrano-Laguna et al., 2012; Yu \& Jo, 2014). Ferguson and Buckingham Shum (2011) proposed an assistance model, which was called Colmena, to support undergraduate students' programming learning. Data extracted from the assistance model helps teachers identify error indicators and visualize student's learning process. Fidalgo-Blanco et al. (2015) utilized learning analytics to assess individual learning progress within the group work. Results showed that learning analytics was effective in monitoring individual progress and teamwork assessment. Lonn et al. (2015) investigated students' academic motivation and designed interventions through learning analytics. Results revealed that learning analytics was an efficient tool in analyzing motivation and designing instructional interventions.

Learning performance prediction. Although a lot of literatures mentioned the possibility of using learning analytics to predict learning performance (AgudoPeregrina et al., 2014; Mattingly et al., 2012), only two studies were conducted to test the possibility of predicting learning through learning analytics. Agudo-Peregrina et al. (2014) utilized learning analytics to predict students' success through log data within virtual learning environment. Results showed a significant relationship between interactions and online learning performance. AgudoPeregrina et al. (2014) suggested that more tools and approaches were required for numerical-based learning analytics in face-toface learning. In fact, this concern was also mentioned in the study by Ellis (2013). Ellis (2013) argued that learning analytics was limited to face-to-face learning because the learning activities and interactions occurred in face-to-face learning were hard to capture and analyze. This might be the reason that few studies were conducted in learning performance prediction.

\subsection{Teaching}

Instructional reflection and intervention. Instruction reflection and intervention design are important topics for teachers. Learning analytics provides the possibility of capturing details of learning behaviors and providing real-time feedback for teachers. Therefore, researchers are very interested in exploring the ways of reflecting teaching and designing instructional interventions through learning analytics (Baepler \& Murdoch, 2010; Clow, 2013; Dyckhoff et al., 2013; Dyckhoff , 2011). Dietz-Uhler and Hurn (2013) suggested that faculty could utilize learning analytics to identify instructional issues and provide appropriate suggestions for students to ensure they can succeed. Wise (2014) proposed four principles of designing pedagogical interventions through learning analytics and three core processes to engage students. Dyckhoff et al. (2012) developed a learning analytics toolkit, which was called eLAT, to support teachers' self-reflection on technologyenhanced teaching. Dyckhoff et al. (2012) also suggested that teachers were able to analyze the instructional data and get real-time alerts from eLAT instead of the tables that were hard to read and understand.

Instructional design. Many researchers have realized that learning analytics has the potential of supporting instructional design (Grant, 2012; Lockyer \& Dawson, 2011). Grant (2012) provided an example of using learning analytics to help faculty improve 
course design. Grant (2012) described that faculty worked together with the instructional designers to revise the online course based on analytical results from LMS. Grant (2012) pointed out real-time information could help teachers support online learning effectively. Lockyer et al., (2013) further explained that instructional design provided the context of interpreting the analytics data through learning objectives and pedagogical goals and, on the contrary, learning analytics provided the possibility of evaluating instructional design within the learning context.

\subsection{Administration}

Data-driven decision making. Utilizing learning analytics to provide data-drive decisions for administrators in higher education is another important research topic. Specifically, student attrition and retention are important research topics related to learning performance. Many researchers dedicated to decrease student attrition and retention (Friesen, 2013; Picciano, 2012; Yasmin, 2013; Sharkey, 2011). However, Ellis (2013) argued that implementation of learning analytics in higher education was limited because the dropout students were only a little part of the entire students population and they shared equal attention with other student populations in the academic work on learning analytics. Therefore, Ellis (2013) suggested assessment analytics because assessment data was already meaningful and ubiquitous.

Besides students' attrition and retention, learning analytics also provides the ability to predict student dropout or detect "at-risk" students for higher education administrators. Yasmin (2013) explored the dropout indicators in distance learning through learning analytics. Results showed that student dropout data were important to motivate students to complete their programs. Dziuban et al.
(2012) described how the University of Central Florida used learning analytics to support strategic planning. Information from university datasets played an important role in assisting the strategic planning process.

\subsection{Technology Development}

Tools/platforms development. Table 2 shows that $38 \%$ of the studies focused on technology development, including platforms development, framework and model development, and data accuracy improvement. Table 1 also demonstrates that external platform is another important data source besides LMS. Although data analytics is widely used in business and other fields, a lot of things need to be done before learning analytics can be fully utilized in higher education. As Long and Siemens (2011) stated, new approaches are "required to understand the patterns of value that exist within the data" (p. 32).

Currently, many researchers in higher education have developed and implemented their own platforms (Dimopoulos et al., 2013; Ferguson \& Buckingham Shum, 2011; Jo et al., 2014; Pardo \& Kloos, 2011; Tabaa \& Medouri, 2013; Verbert et al., 2014; Blikstein, 2011). The most famous self-developed platform and study conducted was the Course Signals project out of Purdue University (Arnold \& Pistilli, 2012). Course Signals, a real-time feedback system, was developed and provided for faculty at Purdue University to evaluate and predict students' performance. Students would get email alerts from faculty to remind them how they were performing in the class. Besides Course Signals, other platforms were developed and tested, such as LeMo (Fortenbacher et al., 2013), HOU2LEARN (Koulocheri \& Xenos, 2013), SCALA (Rayón et al., 2014), and ALAS-KA (RuipérezValiente et al., 2015). 
Model/Framework development. Besides technological platforms, learning model and framework development accounted for $35 \%$ of the technology development studies. Concepts and theories are necessary to support practice. Therefore, many models and frameworks were developed (Ali et al., 2013; Clow, 2012; Dyckhoff et al., 2013; Ifenthaler \& Widanapathirana, 2014; van Barneveld et al., 2012; Wise et al., 2013). Gibson et al. (2014) developed a cognitive processing framework for learning analytics (COPA) to map the cognitive operations within the learning analytics system. Gibson et al. (2014) applied COPA in an undergraduate class and results revealed the effectiveness of identifying potential issues through COPA. With the purpose of providing a systemwide approach for analytics, Siemens (2013) developed the Learning Analytics Model (LAM), which provided a clear picture for researchers to understand how learning analytics was working in higher education.

\subsection{Digital Citizenship}

Ethical and privacy issues. Many researchers mentioned ethical issues and concerns when they discussed learning analytics (Gašević et al., 2015; Prinsloo \& Slade, 2015; Slade \& Galpin, 2012). In fact, ethical issues are inevitable in the digital learning age. Siemens (2013) pointed out that information privacy would be a challenge for future learning analytics implementation in higher education. Kruse and Pongsajapan (2012) suggested a student-centric, inquirybased model where students were the data holders and they used the data to diagnose their own learnings. Kruse and Pongsajapan (2012) also suggested that students should participate in data interpretation and data collection. Pardo and Siemens (2014) proposed four principles of learning analytics deployment to solve ethical issues: transparency, student control over data, right of access, and accountability and assessment. Similar efforts were conducted in the study by Slade and Prinsloo (2013). An ethical framework with six principles was recommended to address digital citizenship issues in higher education (Slade \& Prinsloo, 2013). Slade and Prinsloo (2013) suggested that (a) learning analytics should be considered as moral practice, (b) students should be considered as agents, (c) students' identification and performance should be considered as temporal dynamic constructs, (d) students' success should be complex and multidimensional, and (e) higher education should keep data transparency.

\section{- RQ2: What are the significant results of the learning analytics research in higher education?}

Qualitative descriptions should be included to evaluate and predict learning (Macfadyen \& Dawson, 2012). In addition, considering students' learning objectives and motivation in intervention design is another topic that needs more research efforts. Although learning analytics helps researchers measure learning quantitatively, interpreting the numbers appropriately needs more qualotative research efforts. For instance, longer learning time does not indicate better learning performance. One possibility is that students are confused about the learning content so they need more time. More studies need to be conducted to help educators better understand and utilize learning analytics.

For higher education teaching, currently most studies focus on platforms or tools development and learning evaluation and prediction. Few studies were conducted to explore the possible ways of using learning analytics in teaching. Among 60 publications, articles in teaching only accounted for $17 \%$, which is quite low compared with technology development. No empirical studies were 
conducted in teaching and most studies were theoretical investigation. The most significant results in teaching are the four principles of learning analytics intervention design, which are integration, agency, reference frame, and dialogue, as well as the three core processes of supporting learning, which are grounding, goal setting, and reflection.

Similar to teaching, there are not too many studies at the administration level. This may be caused by the low learning analytics adoption because of the ethical issues. Although some principles and framework were developed to improve ethical issues related to learning analytics in higher education, no practical strategies and methods were provided. Slow improvement of ethical issues caused low learning analytics adoption in higher education. Therefore, few studies were found at the administration level. The most significant application of learning analytics at the administration level is to predict program persistence as illustrated in Table 3.

More than one third of the articles were in technology development, including platforms development and model development. The most significant result in technology development is the development of possible ways of recording learning behaviors occurring outside the LMS. Capturing learning behaviors outside the LMS enables faculty who prefer traditional face-to-face teaching to utilize learning analytics. Another significant finding is the development of learning

Table 3. Significant results of learning analytics research in higher education

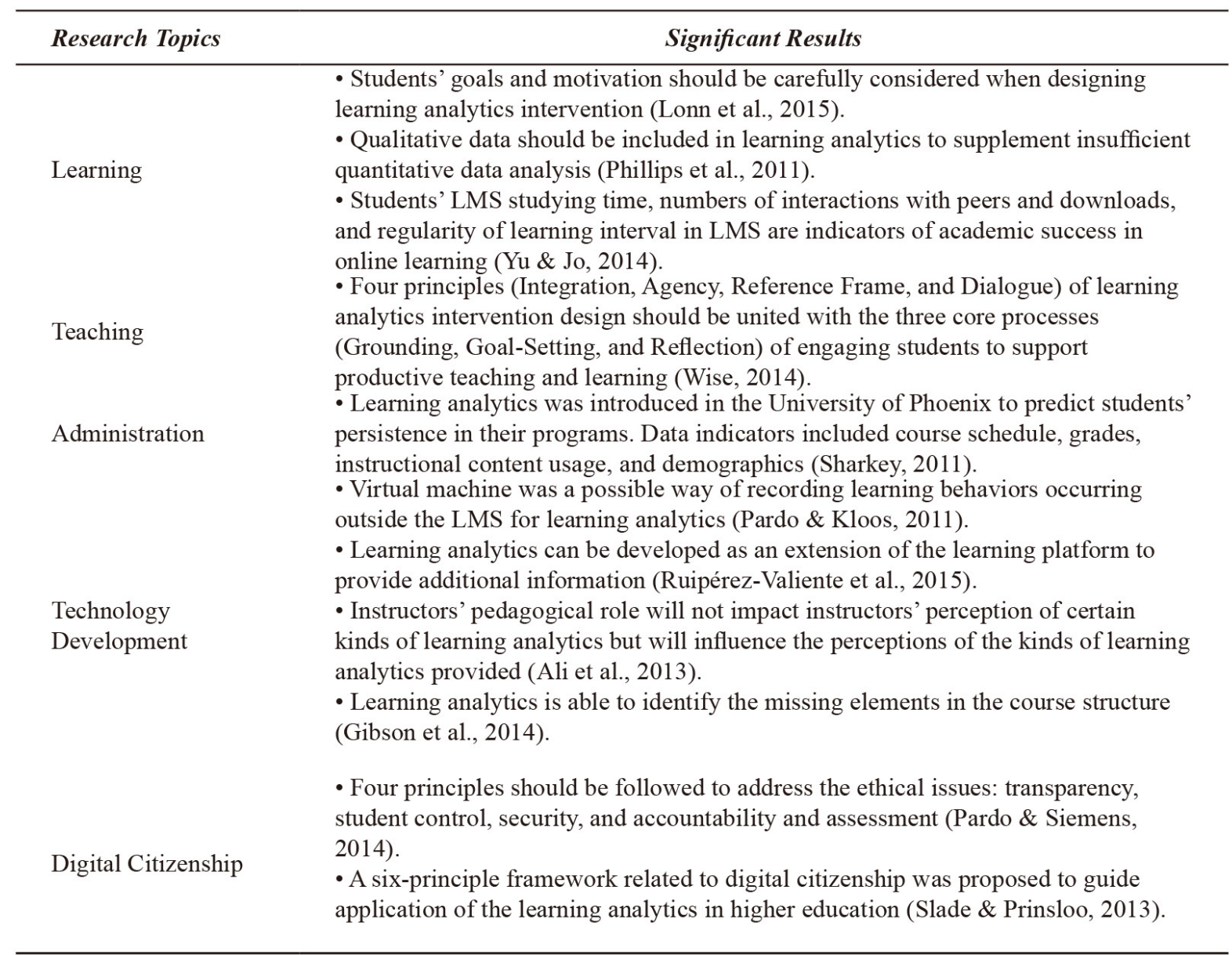


analytics as an extension the learning platform. This may increase learning analytics adoption because users do not need to download and install other software. Faculty, especially who are not good at technology, will feel more comfortable with technology and would like to use learning analytics. All the results are summarized and organized in Table 3.

\section{Implications for Future Research}

\section{- RQ3: What these results indicate for future research?}

Learning Consistency and Motivation. One of the future research directions of learning analytics in higher education is learning consistency. Students can be profiled on the first day they come to the campus and the profiles can be used consistently during their degree programs. In other words, learning analytics can be used to track students' program completions. Future research in the learning analytics field should not be limited to modeling learner performance. Other important learning components, such as motivation, need to be addressed. Learning motivation is not a new research topic in higher education. The importance of motivation in learning has been widely recognized and demonstrated (Kim, Park, Cozart, \& Lee 2015). However, few studies were conducted to explore students' motivation in using a learning analytics approach. Among all the articles that included in this study, there is only one article reported the possibility of using learning analytics to increase learning motivation. Therefore, more studies, especially empirical studies are necessary in this topic.

Data Diversity and Accuracy. Data is important for learning analytics. Where the data comes from and to what extent the data is complete will determine the accuracy of modeling learning and further decide the effectiveness of applying learning analytics in higher education. Currently, learning data is limited to SIS, LMS, library interactions, and other interaction systems. Data generated within these systems may not be the significant learning data (Kruse \& Pongsaijapan, 2012). In addition, one of the concerns related to learning analytics in higher education is the implementation of learning analytics in traditional face-to-face learning (Ellis, 2013). As discussed above, face-to-face instruction is still the primary teaching method in most disciplines and universities. Collecting data from face-to-face learning is a challenge for learning analytics implementation in higher education. Therefore, more data sources are needed for future learning analytics research in higher education. In addition, current university systems are not designed to collect learning data. How to increase data sources and improve model accuracy needs more research. It will be beneficial to investigate how the instructional data from teachers may influence the learning results. Most instructional data included in learning analytics comes from students. However, students are not the only people involved in the learning process. Teachers also play an important role in the learning process. Therefore, it is necessary to include the data generated by teachers. In conclusion, instructional data diversity and accuracy will still be the hot topic in the following years.

Instructional Design and Assessment. Learning analytics is also an effective tool for instructional design assessment. Instructional design assessment used to be an issue for most instructional designers. Most instructional design was evaluated through surveys, questionnaires, and interviews. Learning analytics allows instructional designers to evaluate the learning design within the learning context through real- 
time feedback from the learning analytics system. An instructional designer is able to examine how the instructional design achieves the expected goals with learning analytics. However, few studies discussed the potential of learning analytics in instructional design. Exploring how learning analytics can support instructional design will be an interesting topic for researchers in the field of instructional technology and design. Researchers, especially researchers in instructional design filed, can consider how to utilize learning analytics to support instructional design, such as thinking design, strategy design, activity design, and interaction design.

\section{Conclusion}

This study utilized a systematic review method to investigate how learning analytics has been studied in higher education. Sixty articles were identified according to the selection and assessment rubrics. Results showed that the current research of learning analytics in higher education mainly focuses on technology development, including platforms and model development. There are some improvements in technology development but learning analytics still needs more efforts to explore and develop effective tools or platforms for educators to use in practice. Another important topic of learning analytics is learning, including monitoring learning activities, evaluating learning performance, and predicting learning behaviors. Compared with technology development and learning, few studies were conducted in teaching, administration, and digital citizenship. Inadequate technological support and related ethical issues caused low learning analytics adoption in higher education. In addition, data access permission also limits educators to conduct more studies.

9. Limitations and Future Research
Although the goals of this study were achieved and all the research questions were answered, there are some unavoidable limitations. During the process of paper selection, this study excluded papers that do not have full text access. Therefore, there might have been some articles that met the criteria but were excluded. The selection bias may limit the generalizability of the conclusions in this study. In addition, the difficulty of locating relevant unpublished studies limited the generalizability of this study in other research contexts and settings.

Results of this study contributed to the body knowledge on the current issues and trends in the field of learning analytics. Future research of learning analytics in higher education should focus on learning consistency and motivation improvement, data diversity and accuracy, and instructional design and assessment.

Results of this study contributed to the body knowledge on the current issues and trends in the field of learning analytics. Future research of learning analytics in higher education should focus on learning consistency and motivation improvement, data diversity and accuracy, and instructional design and assessment. 


\section{References}

Agudo-Peregrina, A. F., Iglesias-Pradas, S., Conde-González, M. A., \& HernándezGarcía, A. (2014). Can we predict success from log data in VLEs? Classification of interactions for learning analytics and their relation with performance in VLE-supported F2F and online learning. Computers in Human Behavior, 31(1), 542-550.

Ali, L., Asadi, M., Gašević, D., Jovanović, J., \& Hatala, M. (2013). Factors influencing beliefs for adoption of a learning analytics tool: An empirical study. Computers \& Education, 62(1), 130-148.

Arnold, K. E., \& Pistilli, M. D. (2012). Course signals at Purdue: Using learning analytics to increase student success. Proceedings of the 2nd International Conference on Learning Analytics and Knowledge (LAK '12), Vancouver, BC, Canada, 267-270. doi:10.1145/2330601.2330666

Baepler, P., \& Murdoch, C. J. (2010). Academic analytics and data mining in higher education. International Journal for the Scholarship of Teaching and Learning, 4(2), 1-9.

Barber, R., \& Sharkey, M. (2012). Course correction: Using analytics to predict course success. Proceedings of the 2 nd International Conference on Learning Analytics and Knowledge (LAK '12), Vancouver, BC, Canada, 259-262. doi:10.1145/2330601.2330664

Blikstein, P. (2011). Using learning analytics to assess students' behavior in openended programming tasks. Proceedings of the 1st International Conference on Learning Analytics and Knowledge (LAK '11), Banff, AB, Canada, 110-116. doi:10.1145/2090116.2090132

Calof, J., Richards G., \& Smith J. (2015). Foresight, competitive intelligence and business analytics-Tools for making industrial programmes more efficient. Foresight-Russia, 9(1), 68-81.

Campbell, J. P., DeBlois, P. B., \& Oblinger, D. G. (2007). Academic analytics: A new tool for a new era. EDUCAUSE Review, 42(4), 40-57.

Clow, D. (2012). The learning analytics cycle: Closing the loop effectively. Proceedings of the 2nd International Conference on Learning Analytics and Knowledge (LAK '12), Vancouver, BC, Canada, 134-138. doi:10.1145/2330601.2330636

Clow, D. (2013). An overview of learning analytics. Teaching in Higher Education, 18(6), 683-695.

de Laat, M., \& Prinsen, F. R. (2014, Winter). Social learning analytics: Navigating the changing settings of higher education. Research \& Practice in Assessment, 9, 51-60.

Dietz-Uhler, B., \& Hurn, J. E. (2013). Using learning analytics to predict (and improve) student success: A faculty perspective. Journal of Interactive Online Learning, 12(1), 17-26.

Dimopoulos, I., Petropoulou, O., \& Retalis, S. (2013). Assessing students' performance using the learning analytics enriched rubrics. Proceedings of the 3rd International Conference on Learning Analytics and Knowledge (LAK '13), Leuven, Belgium, 195-199. doi:10.1145/2460296.2460335

Dyckhoff, A. L. (2011). Implications for learning analytics tools: A meta-analysis of applied research questions. International Journal of Computer Information Systems and Industrial Management Applications, 3(1), 594-601.

Dyckhoff, A. L., Lukarov, V., Muslim, A., Chatti, M. A., \& Schroeder, U. (2013). Supporting action research with learning analytics. Proceedings of the 3rd International Conference on Learning Analytics and Knowledge 
(LAK '13), Leuven, Belgium, 220-229. doi:10.1145/2460296.2460340

Dyckhoff, A. L., Zielke, D., Bültmann, M., Chatti, M. A., \& Schroeder, U. (2012). Design and implementation of a learning analytics toolkit for teachers. Educational Technology \& Society, 15(3), 58-76.

Dziuban, C., Moskal, P., Cavanagh, T., \& Watts, A. (2012). Analytics that inform the university: Using data you already have. Journal of Asynchronous Learning Networks, 16(3), 21-38.

Ellis, C. (2013). Broadening the scope and increasing the usefulness of learning analytics: The case for assessment analytics. British Journal of Educational Technology, 44(4), 662-664.

Ferguson, R., \& Buckingham Shum, S. (2011). Learning analytics to identify exploratory dialogue within synchronous text chat. Proceedings of the 1st International Conference on Learning Analytics and Knowledge (LAK '11), Banff, AB, Canada, 99-103. doi:10.1145/2090116.2090130

Fernandez-Medina, C., Pérez-Pérez, J. R., Álvarez-García, V. M., \& del Puerto Paule-Ruiz, M. (2013). Assistance in computer programming learning: Using educational data mining and learning analytics. Proceedings of the 18th ACM Conference on Innovation and Technology in Computer Science Education (ITiCSE ' 13 ), Canterbury, UK, 23 7-242. doi:10.1145/2462476.2462496

Fidalgo-Blanco, A., Sein-Echaluce, M. L., García-Peñalvo, F. J., \& Conde, M. A. (2015). Using learning analytics to improve teamwork assessment. Computers in Human Behavior, 47(1), 149-156.

Fortenbacher, A., Beuster, L., Elkina, M., Kappe, L., Merceron, A., Pursian, A., Schwarzrock, S., \& Wenzlaff, B. (2013). LeMo: A learning analytics application focusing on user path analysis and interactive visualization. Proceedings of the 7th IEEE International Conference on Intelligent Data Acquisition and Advanced Computing Systems (IDAACS), 2013 IEEE, Berlin, Germany, 748-753. doi:10.1109/IDAACS.2013.6663025

Friesen, N. (2013). Learning analytics: Readiness and rewards. Canadian Journal of Learning and Technology, 39(4), 1-12.

Gašević, D., Dawson, S., \& Siemens, G. (2015). Let's not forget: Learning analytics are about learning. TechTrends, 59(1), 64-71.

Gibson, A., Kitto, K., \& Willis, J. (2014). A cognitive processing framework for learning analytics. Proceedings of the 4th International Conference on Learning Analytics and Knowledge (LAK '14), Indianapolis, IN, USA, 212-216. doi:10.1145/2567574.2567610

Grant, M. R. (2012). University of MissouriSt. Louis: Data-driven online course design and effective practices. Continuing Higher Education Review, 76(1), 183192.

Hernández-García, A., González-González, I., Jiménez-Zarco, A. I., \& ChaparroPeláez, J. (2015). Applying social learning analytics to message boards in online distance learning: A case study. Computers in Human Behavior, 47(1), 68-80.

Ifenthaler, D., \& Widanapathirana, C. (2014). Development and validation of a learning analytics framework: Two case studies using support vector machines. Tech Know Learn, 19(1-2), 221-240.

Jo, I.-H., Kim, D., \& Yoon, M. (2014). Analyzing the $\log$ patterns of adult learners in LMS using learning analytics. Proceedings of the $4 \mathrm{th}$ International Conference on Learning Analytics and Knowledge (LAK '14), Indianapolis, IN, USA, 183-187. doi:10.1145/2567574.2567616

Khan, K. S., Kunz, R., Kleijnen, J., \& Antes, 
G. (2003). Five steps to conducting a systematic review. Journal of the Royal Society of Medicine, 96(3), 118-121.

Kim, C., Park, S. W., Cozart, J., \& Lee, H. (2015). From motivation to engagement: The role of effort regulation of virtual high school students in Mathematics courses. Educational Technology \& Society, 18(4), 261-272.

Koulocheri, E., \& Xenos, M. (2013). Considering formal assessment in learning analytics within a PLE: The HOU2LEARN case. Proceedings of the 3rd International Conference on Learning Analytics and Knowledge (LAK '13), Leuven, Belgium, 28-32. doi:10.1145/2460296.2460304

Kruse, A., \& Pongsajapan, R. (2012). Student-centered learning analytics. CNDLS Thought Papers, 1-9. Retrieved from https://cndls.georgetown. edu/m/documents/thoughtpaperkrusepongsajapan.pdf.

Lockyer, L., \& Dawson, S. (2011). Learning design and learning analytics. Proceedings of the 1st International Conference on Learning Analytics and Knowledge (LAK '12), Banff, AB, Canada, 153-156. doi:10.1145/2090116.2090140

Lockyer, L., Heathcote, E., \& Dawson, S. (2013). Informing pedagogical action: Aligning learning analytics with learning design. American Behavioral Scientist, 57(10), 1439-1459.

Long, P., \& Siemens, G. (2011). Penetrating the fog: Analytics in learning and education. EDUCAUSE Review, 46(5), 31-40.

Lonn, S., Aguilar, S. J., \& Teasley, S. D. (2015). Investigating student motivation in the context of a learning analytics intervention during a summer bridge program. Computers in Human Behavior, 47(1), 90-97.

Ma, J., Han, X., Yang, J., \& Cheng, J. (2015).
Examining the necessary condition for engagement in an online learning environment based on learning analytics approach: The role of the instructor. Internet and Higher Education, 24(1), 26-34.

Macfadyen, L. P., \& Dawson, S. (2012). Numbers are not enough. Why e-learning failed to inform an institutional strategic plan. Educational Technology \& Society, 15(3), 149-163.

Mattingly, K. D., Rice, M. C., \& Berge, Z. L. (2012). Learning analytics as a tool for closing the assessment loop in higher education. Knowledge Management \& E-Learning: An International Journal, 4(3), 236-247.

Olmos, M., \& Corrin, L. (2012). Learning analytics: A case study of the process of design of visualizations. Journal of Asynchronous Learning Networks, 16(3), 39-49.

Pardo, A., \& Kloos, C. D. (2011). Stepping out of the box: Towards analytics outside the learning management system. Proceedings of the 1st International Conference on Learning Analytics and Knowledge (LAK '11), Banff, AB, Canada, 163-167. doi:10.1145/2090116.2090142

Pardo, A., \& Siemens, G. (2014). Ethical and privacy principles for learning analytics. British Journal of Educational Technology, 45(3), 438-450.

Phillips, R., Maor, D., Cumming-Potvin, W., Roberts, P., Herrington, J, Preston, G., Moore, E., \& Perry, L. (2011). Learning analytics and study behaviour: A Pilot study. In Changing demands, changing directions: Proceedings Ascilite Hobart 2011, 997-1007. Retrieved from http:// www.ascilite.org.au/conferences/ hobart11/downloads/papers/Phillips-full. pdf.

Picciano, A. G. (2012). The evolution of big data and learning analytics in American 
higher education. Journal of Asynchronous Learning Networks, 16(3), 9-20.

Prinsloo, P., \& Slade, S. (2015). Student privacy self-management: Implications for learning analytics. Proceedings of the 5th International Conference on Learning Analytics and Knowledge (LAK '15), Poughkeepsie, NY, USA, 83-92. doi:10.1145/2723576.2723585

Prinsloo, P., Slade, S., \& Galpin, F. (2015). Learning analytics-Challenges, paradoxes and opportunities for mega open distance learning institutions. Proceedings of the 2nd International Conference on Learning Analytics and Knowledge (LAK '12), Vancouver, BC, Canada, 130-133. http:// dx.doi.org/10.1145/2330601.2330635

Rayón, A., Guenaga, M., \& Núñez, A. (2014). Supporting competency-assessment through a learning analytics approach using enriched rubrics. Proceedings of the Second International Conference on Technological Ecosystems for Enhancing Multiculturality (TEEM '14), Salamance, Spain, 291-298. doi:10.1145/2669711.2669913

Ruipérez-Valiente, J. A., Muñoz-Merino, P. J., Leony, D., \& Kloos, C. D. (2015). ALAS-KA: A learning analytics extension for better understanding the learning process in the Khan Academy platform. Computers in Human Behavior, 47(1), 139-148.

Serrano-Laguna, A., Torrente, J., MorenoGer, P., \& Fernández-Manjón, B. (2012). Tracing a little for big improvements: Application of learning analytics and videogames for student assessment. Procedia Computer Science, 15(1), 203209.

Serrano-Laguna, A., Torrente, J., MorenoGer, P., \& Fernández-Manjón, B. (2014). Application of learning analytics in educational videogames. Entertainment Computing, 5(4), 313-322.
Sharkey, M. (2011). Academic analytics landscape at the University of Phoenix. Proceedings of the $1 \mathrm{st}$ International Conference on Learning Analytics and Knowledge (LAK '11), Banff, AB, Canada, 122-126. doi:10.1145/2090116.2090135

Siemens, G. (2013). Learning analytics: The emergence of a discipline. American Behavioral Scientist, 57(10), 1380-1400.

Slade, S., \& Galpin, F. (2012). Learning analytics and higher education: Ethical perspectives. Proceedings of the 2 nd International Conference on Learning Analytics and Knowledge (LAK '12), Vancouver, BC, Canada, 16-17. doi:10.1145/2330601.2330610

Slade, S., \& Prinsloo, P. (2013). Learning analytics ethical issues and dilemmas. American Behavioral Scientist, 57(10), 1510-1529.

Tabaa, Y., \& Medouri, A. (2013). LASyM: A learning analytics system for MOOCs. International Journal of Advanced Computer Science and Applications, 4(5), 113-119.

van Barneveld, A., Arnold, K. E., \& Campbell, J. P. (2012). Analytics in higher education: Establishing a common language. EDUCAUSE Learning Initiative, 1(1), $1-11$.

Verbert, K., Govaerts, S., Duval, E., Santos, J. L., Van Assche, F., Parra, G., \& Klerkx, J. (2014). Learning dashboards: An overview and future research opportunities. Personal and Ubiquitous Computing, 18(6), 14991514.

Wills, M. J. (2014). Decisions through data: Analytics in healthcare. Journal of Healthcare Management, 59(4), 254-262.

Wise, A. F. (2014). Designing pedagogical interventions to support student use of learning analytics. Proceedings of the 4th International Conference on Learning Analytics and Knowledge (LAK 
'14), Indianapolis, IN, USA, 203-211. doi: $10.1145 / 2567574.2567588$

Wise, A. F., Zhao, Y., \& Hausknecht, S. N. (2013). Learning analytics for online discussions: A pedagogical model for intervention with embedded and extracted analytics. Proceedings of the 3rd International Conference on Learning Analytics and Knowledge (LAK '13), Leuven, Belgium, 48-56. doi:10.1145/2460296.2460308

Yasmin, D. (2013). Application of the classification tree model in predicting learner dropout behaviour in open and distance learning. Distance Education, 34(2), 218-231.

Yu, T., \& Jo, I. (2014). Educational technology approach toward learning analytics: Relationship between student online behavior and learning performance in higher education. Proceedings of the 4th International Conference on Learning Analytics and Knowledge (LAK '14), Indianapolis, IN, USA, 269-270. doi:10.1145/2567574.2567594

\section{Contact the Author}

\section{Lin Zhong}

The University of Southern Mississippi Email: lin.zhong@eagles.usm.edu 